\title{
The Effects of Maintaining Temperature in Annealing Heat Treatment for an FSWed 6061-T6 Al Alloy
}

\author{
Seung-Jun Lee, Min-Su Han, and Seong-Jong Kim \\ Division of Marine System Engineering, Mokpo Maritime University, Haeyangdaehak-ro 91 Mokpo-si, \\ Jeonnam 530-729, Korea
}

\begin{abstract}
The technological development of all kinds of lightweight transportation devices including vehicles, aircraft, ships, etc. has progressed markedly with the demand for energy saving and environmental protection. Aluminum alloy is in the spotlight as it is a suitable environmentally friendly material. However, deformation is a major problem during the welding process because aluminum alloy has a large thermal expansion coefficient. In addition, it is known that its corrosion resistance is excellent; nevertheless, in practice, considerable corrosion is generated and this is a major problem. To solve this problem, the friction stir welding (FSW) technology is applied extensively at various industrial fields as a new welding technique. This method involves a process in which materials are joined by frictional heat and physical force. Therefore, we evaluated improvements in mechanical properties and corrosion resistance through annealing heat treatment after FSW. The electrochemical experiment did not show a significant difference. However, the microstructure observation showed defectless, fine crystal particles, indicating excellent properties at $200-225^{\circ} \mathrm{C}$.
\end{abstract}

Key words: annealing heat treatment, friction stir welding (FSW), Al-Mg-Si alloy, seawater, microstructure, corrosion

\section{INTRODUCTION}

Friction stir welding (FSW) refers to welding where the material around the probe is softened by frictional heat and the workpiece is welded as the material on both sides of the weld surface is physically mixed with the plastic flow that is caused by stirring the probe (Dawes, 1995; Thomas \& Dawes, 1996; Knipstrom \& Pekkari, 1997; Chen \& Kovacevic, 2004; Uzun et al., 2005). This welding method yields better mechanical properties than those of the conventional fusion welding method and forms an excellent welding zone. Since the heat input is less than that of the conventional fusion welding with the use of friction heat between the welding probe and the specimen, FSW has advantages such as low residual stress and small deformation. However, according to conventional studies, the welding zone is good but the mechanical strength is low in the FSWed 6061-T6 Al alloy. Therefore, we evaluated improvements in mechanical properties and corrosion resistance by annealing heat treatment after FSW.

\section{Materials and Methods}

In this study, the FSW was carried out for a 6061-T6 alloy of 5t (thickness) that is used for the body of vehicles or the upper structure of ships. The dimensions of the probe used were as follows: $\varnothing 20 \mathrm{~mm}$ for the shoulder, $4.5 \mathrm{~mm}$ probe length, $\varnothing 5 \mathrm{~mm}$ diameter, and $1 \mathrm{~mm}$ pitch, and the probe rotated counterclockwise. For welding, we used an HMK-3D milling machine. The tilting angle, traveling, and rotating speed applied for welding were $3^{\circ}, 507 \mathrm{~mm} / \mathrm{min}$, and 1,100

() MICROSCOPY SOCIETY OF AMERICA 2013

${ }^{\star}$ Corresponding author. E-mail: ksj@mmu.ac.kr rpm, respectively, as established previously for a 6061-T6 Al alloy (Kim \& Jang, 2008). The annealing heat-treatment temperature was $200-400^{\circ} \mathrm{C}$ for $2 \mathrm{~h}$, followed by air cooling. Hardness was measured by observing the plastic deformation behavior by FSW. A specimen larger than $25 \mathrm{~mm}$ was etched into the cross-sectional parts from the center of the welding zone and a $9.807 \mathrm{~N}$ load was applied using a micro-Vickers hardness tester, maintaining the load application for $10 \mathrm{~s}$. The measurement was repeated more than three times at $1 \mathrm{~mm}$ intervals, and the mean values were compared. Surface etching was performed by dipping the specimen in Keller solution used for macro-etching for several seconds to minutes. Tafel analysis was used to determine the corrosion potential and corrosion current density by polarizing $\pm 0.25 \mathrm{~V}$ based on the open circuit potential.

\section{Results And Discussion}

Figure 1 compares the plastic flow behavior after annealing heat treatment of the FSWed 6061-T6 Al specimen $(1,100$ $\mathrm{rpm}, 507 \mathrm{~mm} / \mathrm{min}$ ) for $120 \mathrm{~min}$ at various temperatures. In Figure 1, (a) shows the base metal, (b) shows the heataffected zone, (C) shows the stir zone where dynamic crystallization occurred with frictional heat and plastic flow by direct stirring between the probe and the material and (d) shows the boundary surface between the nugget and the thermomechanical affected zone. In the base metal, a clear grain boundary was found among the precipitates with corrosion by etching under most of the conditions. The finest crystal particles of $60-70 \mu \mathrm{m}$ size were found at $225^{\circ} \mathrm{C}$. At a temperature of $300^{\circ} \mathrm{C}$, a Si solid solution was not found as it had dissolved in the base metal. At a temperature above $400^{\circ} \mathrm{C}$, the crystallized particle size was 

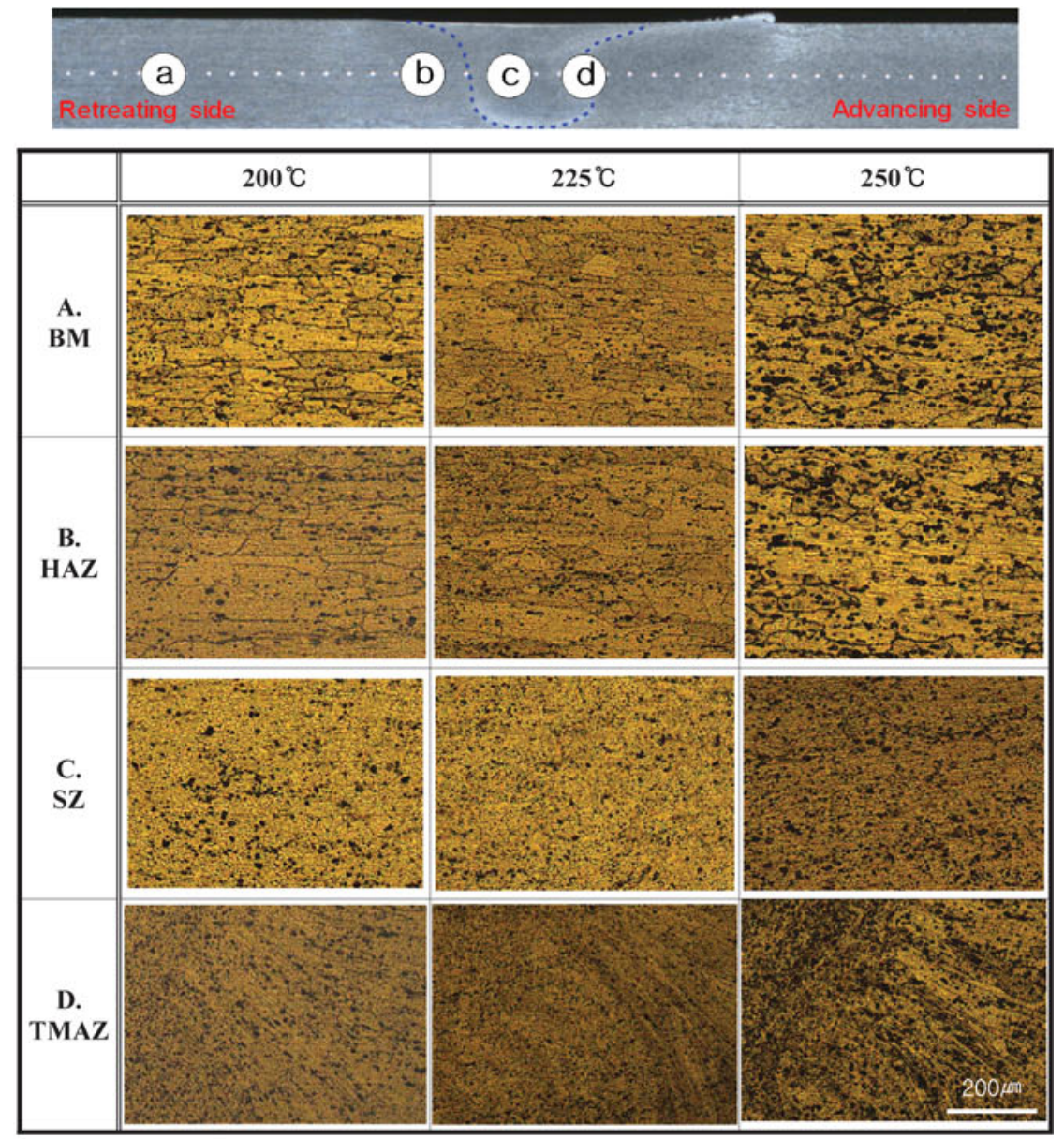

(a) $200^{\circ} \mathrm{C} \sim 250^{\circ} \mathrm{C}$

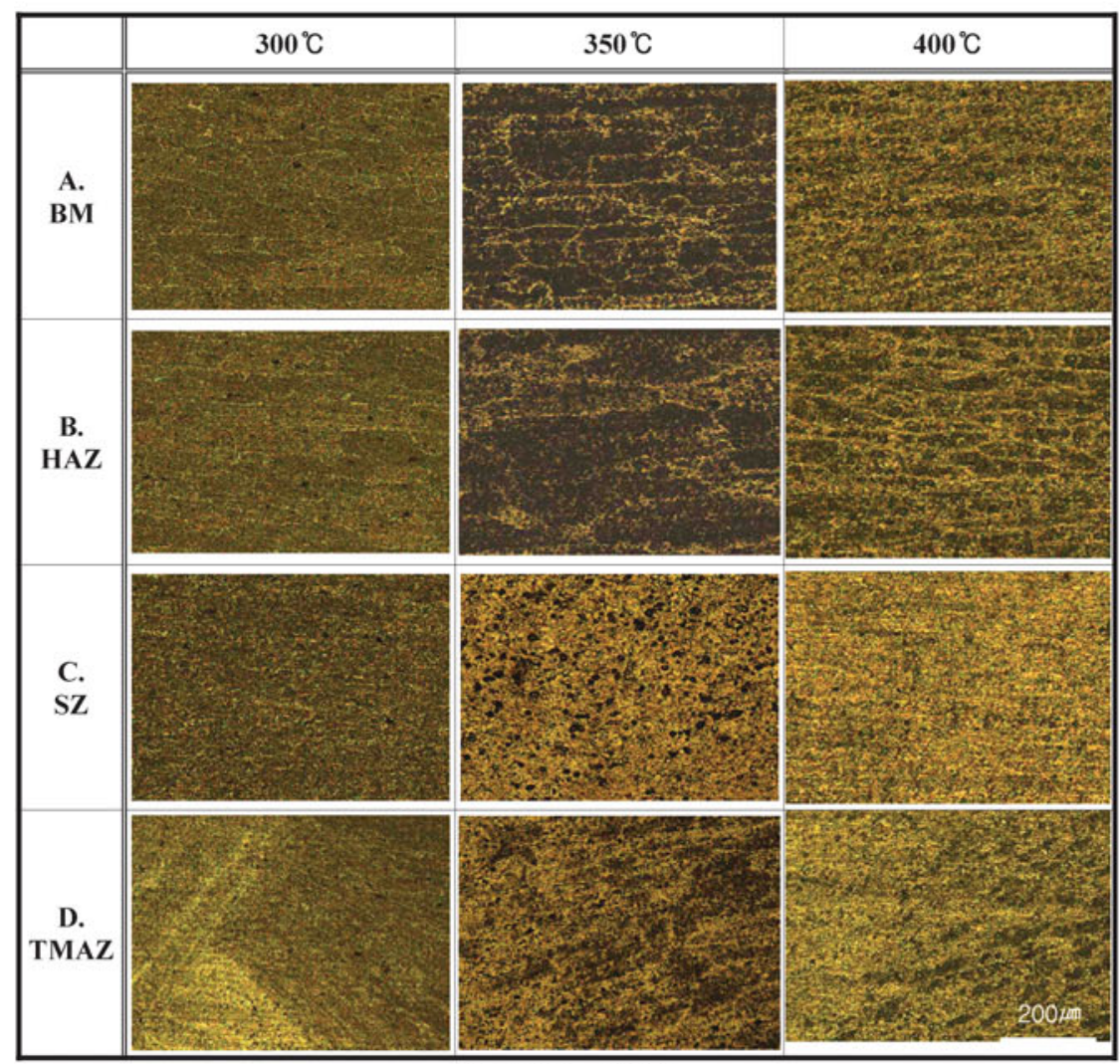

(b) $300^{\circ} \mathrm{C} \sim 400^{\circ} \mathrm{C}$
Figure 1. Comparison of microstructures with annealing temperature for FSWed 6061-T6 Al alloy. (a) $200-250^{\circ} \mathrm{C}$ and (b) $300-400^{\circ} \mathrm{C}$. 


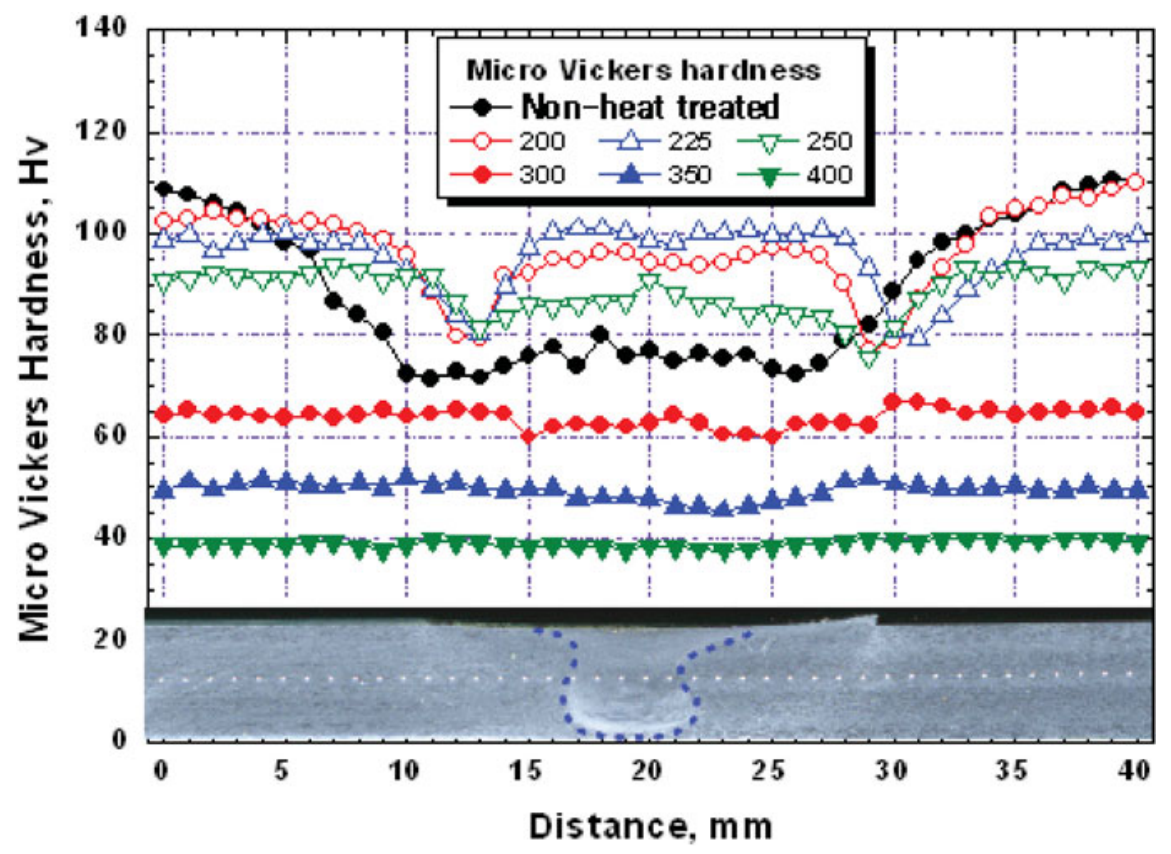

Figure 2. Comparison of micro-Vickers hardness with annealing temperature for the FSWed 6061-T6 Al alloy.

small. In the case of the heat-affected zone, which is the zone affected only by frictional heat without direct contact with the probe, the crystallized particle became coarser than that in the base metal under all the conditions. The crystallized particles further increased in size until the mean crystal particle size became $120-150 \mu \mathrm{m}$ at $350^{\circ} \mathrm{C}$. However, at $400^{\circ} \mathrm{C}$, the crystallized particle size was as fine as $225^{\circ} \mathrm{C}$ due to softening at the high temperature. In the stir zone, the crystal structure particle was much finer than that in the base metal under all the conditions because of recrystallization due to frictional heat and mechanical flow. In the case of the thermomechanical affected zone, the structure was aligned in the diagonal direction by plastic deformation and local recrystallization.

Figure 2 shows the hardness measured at a $1 \mathrm{~mm}$ interval using the micro-Vickers hardness tester following annealing heat treatment for $120 \mathrm{~min}$ at various temperatures on the FSWed 6061-T6 Al alloy specimens. The base metal that was not heat treated showed a mean hardness of $110 \mathrm{HV}$. Under $200^{\circ} \mathrm{C}$ heat treatment, the hardness of the stir zone, which was directly affected by the probe, was 96 $\mathrm{HV}$, which was $87 \%$ of the base metal hardness, indicating a reduction in hardness by $23 \mathrm{HV}$. In particular, the hardness of the heat-affected zone was markedly reduced to about 78-96 HV, which indicated that frictional heat generated by the stirring might have contributed toward the growth of crystal particles. At $225^{\circ} \mathrm{C}$, the hardness of the stir zone had increased probably because the crystal particles became finer than the base metal. It is assumed that the hardness was reduced in the heat-affected zone because the crystal particles became coarse because of friction heat flowing to the inside and the effect of the annealing. At $250^{\circ} \mathrm{C}$, the reduction in the hardness was greater in the heat-affected zone than that in the stir zone. This may have been because the crystal particles became fine in the stir zone due to the rotation of the probe, while the crystal particles became coarse in the heat-affected zone because of the frictional heat generated by the rotation of the probe. During heat treatment at temperatures above $300^{\circ} \mathrm{C}$, the difference in hardness among various parts became negligible as they were softened by the high temperature. The hardness distribution of the FSWed 6061-T6 Al alloy specimens was compared after annealing heat treatment at various temperatures. The hardness measured in the stir zone at 200, 225, and $250^{\circ} \mathrm{C}$ was significantly higher than that of the non-heattreated specimens, which may have been because of the formation of an $\mathrm{Mg}_{2} \mathrm{Si}$ intermetallic compound by Si element diffusion and recrystallization by annealing heat treatment. The hardness was significantly lower at the annealing temperature of $300^{\circ} \mathrm{C}$ than in the non-heat-treated specimens. In particular, the hardness in the base metal was almost 50 HV lower. This was because the crystal particles became coarse because of the annealing. The mean hardness reduced gradually as the temperature increased. It can be concluded that there is almost no difference in the hardness among the microstructures as they are softened by high temperatures above $300^{\circ} \mathrm{C}$. Under all the conditions, the hardness was slightly higher in the stir zone than in the heat-affected zone and the thermomechanical affected zone. It is known that such an increase in hardness in the stir zone is because of natural aging after the welding as the stir zone is exposed to the temperature around the melting temperature and the solute atoms are supersaturated in the solid solution by heat and plastic flow.

Figure 3 compares the corrosion potential and the corrosion current density by Tafel analysis at annealing heat-treatment temperatures for the FSWed 6061-T6 Al alloy base metal. A comparison of the corrosion potential in 


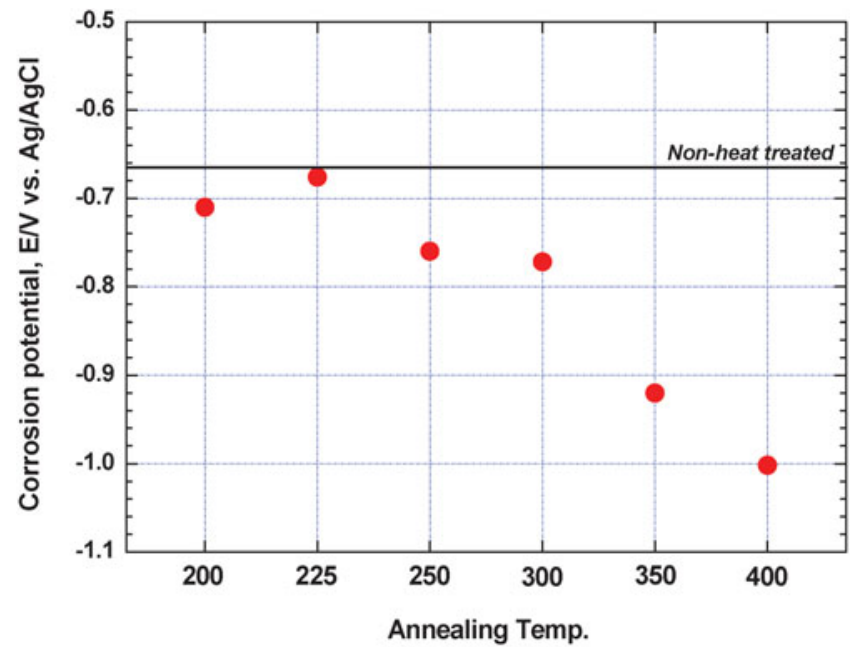

(a) Corrosion potential

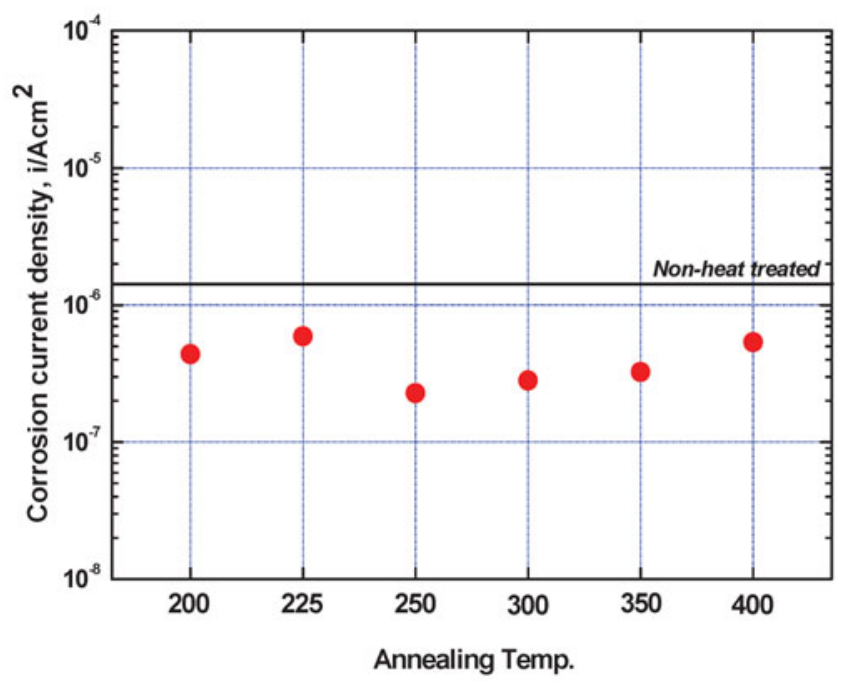

(b) Corrosion current density

Figure 3. Results of Tafel analysis of BM for the FSWed 6061-T6 $\mathrm{Al}$ alloy with annealing temperature: (a) corrosion potential and (b) corrosion current density.

Figure 3a shows that the corrosion potential was nobler as the temperature was lower. Hence, a temperature of $225^{\circ} \mathrm{C}$ can be considered the most stable electrochemically because its corrosion potential was the most noble. The corrosion potential, however, does not provide useful information when a single metal is exposed to corrosive environment, and in that case the corrosion current density has a significant effect on corrosion behavior. Comparison of the corrosion current density in Figure 3b shows that at higher corrosion current density, the corrosion rate is high and corrosion occurs more easily in the seawater environment. Thus, the low corrosion current density at the temperature above $250^{\circ} \mathrm{C}$ can be considered good, and the corrosion rate may the highest at $225^{\circ} \mathrm{C}$ since the corrosion current density was the highest among various temperatures. However, there may not be a large difference in the corrosion rate in practice because the difference was very small.

\section{CONCLUSION}

FSWed 6061-T6 alloy specimens were compared after $2 \mathrm{~h}$ of annealing heat treatment at $200-400^{\circ} \mathrm{C}$, but the electrochemical experiment did not show a significant difference. The hardness of the heat-treated specimen at 200 and $225^{\circ} \mathrm{C}$ showed almost no difference from that of the non-heattreated specimen or showed slightly higher hardness. The microstructure observation also showed defectless, fine crystal particles, indicating excellent properties. Therefore, it is assumed that the optimum annealing temperature for the FSWed $6061-\mathrm{T} 6 \mathrm{Al}$ alloy is $200-225^{\circ} \mathrm{C}$.

\section{RefERENCES}

Chen, M. \& Kovacevic, R. (2004). Joining of Al 6061 alloy to AISI 1018 steel by combined effects of fusion and solid state welding. Int J Mach Prob Manu 44, 1205-1214.

DAwES, C.J. (1995). An introduction to friction stir welding and its development. Weld Met Fabr 63, 13-16.

KIM, S.J. \& JANG, S.K. (2008). Evaluation of electrochemical characteristic and investigation on optimum condition in friction stir welding for 6061-T6 Al alloy. J Kor Inst Surf Eng 41, 341-350.

Knipstrom, K.E. \& Pekkari, B. (1997). Friction stir welding process goes commercial. Weld J 76, 55-57.

Thomas, W.M. \& Dawes, C.J. (1996). Friction stir process welds of aluminum alloys. Weld $J$ 75, 41-45.

Uzun, H., Donne, C.D., Argagnotto, A., Ghidini, T. \& GamBARo, C. (2005). Friction stir welding of dissimilar Al 6013-T4 to X5CrNi18-10 stainless steel. Mater Des 26, 41-46. 